\title{
The Effect of Epoxy Concentration and Fibre Loading on the Mechanical Properties of ABS/Epoxy-Coated Kenaf Fibre Composites
}

\author{
Hafsat R. Saliu1 ${ }^{*}$, U. S. Ishiaku1, M. K. Yakubu'1, E. G. Kolawole1, S. S. Adefila², \\ M. B. Abu Bakar', Z. A. Moh'd Ishak ${ }^{3}$ \\ ${ }^{1}$ Department of Textile Science and Technology, Ahmadu Bello University, Zaria, Nigeria \\ ${ }^{2}$ Department of Chemical Engineering, Ahmadu Bello University, Zaria, Nigeria \\ ${ }^{3}$ School of Materials and Mineral Resources Engineering, Engineering Campus, Universiti Sains Malaysia, \\ Penang, Malaysia \\ Email: hrsaliu@abu.edu.ng
}

Received 20 January 2015; accepted 13 April 2015; published 16 April 2015

Copyright (C) 2015 by authors and Scientific Research Publishing Inc.

This work is licensed under the Creative Commons Attribution International License (CC BY).

http://creativecommons.org/licenses/by/4.0/

(c) (i) Open Access

\begin{abstract}
In this work, thermosetting resin, epoxy and fibre loading were used in optimizing the strength at which ABS/epoxy coated kenaf fibre (EKF) composites would perform apparently during mechanical stress. Kenaf bast fibres were resin coated before incorporated into engineering thermoplastic $\mathrm{ABS}$ at its processing temperature $\left(230^{\circ} \mathrm{C}\right)$, cured in-situ at internal mixer and later compression moulded at $210^{\circ} \mathrm{C}$ under $65 \mathrm{~kg} / \mathrm{cm}^{2}$ pressure. The results showed the optimum level of tensile strength with thermoset and fibre loading as well as increase in strong interfacial bonding while the hardness values increased with increasing thermosetting and fibre contents. Both the tensile and flexural modulus apparently increased as the fibre contents increased.
\end{abstract}

\section{Keywords}

Thermosetting Resin, Kenaf Fibre, Engineering Thermoplastic, ABS

\section{Introduction}

Epoxy resins are one of the most important thermosetting polymers, which find extensive use as coatings, matrix resins for composite materials and high performance adhesives. They have various desirable properties such as high tensile strength and modulus, good thermal and chemical resistance and dimensional stability by Hedrick et

\footnotetext{
"Corresponding author.
}

How to cite this paper: Saliu, H.R., Ishiaku, U.S., Yakubu, M.K., Kolawole, E.G., Adefila, S.S., Abu Bakar, M.B. and Moh'd Ishak, Z.A. (2015) The Effect of Epoxy Concentration and Fibre Loading on the Mechanical Properties of ABS/Epoxy-Coated Kenaf Fibre Composites. Open Journal of Composite Materials, 5, 41-48. http://dx.doi.org/10.4236/ojcm.2015.52007 
al. [1]. However, in many applications they have the major drawbacks of being very brittle, poor thermal cycling behaviour and fairly low impact and fracture strengths. They also show high moisture absorption, which limits their performance. Another approach has been taken to modify the epoxy resins which seem to provide better improvement in the overall properties of the resulting networks without any significant loss in the modulus. Tough, ductile, chemically and thermally stable engineering thermoplastics such as polyethersulfones and polyether-imides have been utilized. These materials have no reactive functional groups so they simply physically blend into the epoxy resin to be cured. It has been reported that some improvement in the fracture toughness is obtained provided that a phase separation with good interfacial adhesion is achieved (Hedrick et al., [1]). The fibre surface treatment before introducing the matrixmaterial can modify the interphase region and alter the adhesion between the fibre and the matrix. The adsorption of the epoxy resin on the jute fibre surface is ensured, which is a prerequisite condition for creating the interphases (George et al., [2]).

The inherent polar and hydrophilic nature of lignocellulosic fibres and the non-polar characteristics of most thermoplastics result in compounding difficulties leading to non-uniform dispersion of fibres within the matrix which impairs the efficiency of the composite. This is a major disadvantage of natural fibre reinforced composites. The combination of a plastic matrix and reinforcing fibres gives rise to composites having the best properties of each component. Since the plastics are soft, flexible and lightweight in comparison to fibres, their combination provides a high strength-to-weight ratio to the resulting composite. Bos and Donald [3] explained that the properties of the fibres were determined by the physical, mechanical and chemical properties of the morphological constituents and their interfaces as agreed by Thakur and Singha [4]. These same properties have been found to be the most trusted tools in determining the overall behaviour of polymer composites.

The interest in natural fibre-reinforced polymer composite materials is rapidly growing both in terms of their industrial applications and fundamental research (Kozlowski and Wladyka-Przybylak [5] [6]; Bledzki and Gassan [7] and Thomas [8]). They are renewable, cheap, completely or partially recyclable, and biodegradable. Plants, such as flax, cotton, hemp, jute, sisal, kenaf, pineapple, ramie, bamboo, and banana, as well as wood, used from time immemorial as a source of lignocellulosic fibres, are more often applied as the reinforcement of composites. The natural fibre-containing composites are more environmentally friendly, and are used in transportation (automobiles, railway coaches, aerospace), military applications, building and construction companies (ceiling panelling, partition boards), packaging, consumer products, etc.

Kenaf plant is an annual plant that can be harvested 2 - 3 times a year. It can grow to reach 3 - 4 meters within 4 - 5 months and has three layers - bast, core, and pith. Kenaf bast fibre has been reported to have superior mechanical properties than the other parts of the plant (Aji et al., [9]). The kenaf bast fibre has high potential as a reinforcing fibre in thermoplastic composites because of its superior toughness and high aspect ratio in comparison with other fibres. The kenaf bast fibre is a composite made up of a crystalline, thermoset polymer matrix (lignin and the hemicelluloses). The chemical modification of the fibre was studied by Rowell et al., [10] to make it more hydrophobic, and it improved its compatibility with non-polar thermoplastics. Sanadi et al. [11] studied the potential of kenaf as a reinforcing fibre in the PP matrix. El-Shekeil and co-researchers [12] studied the development of new kenaf bast fibre-reinforced thermoplastic polyurethane composite, and reported that the thermoplastic polyurethane (TPU) had unique properties when compounded with natural fibres and it was established that the kenaf filled composites showed high tensile strength, break strain and modulus of elasticity properties, but least absorbed water (Karina et al., [13]). Anuar and Zuraida, [14] studied the thermal properties of Injection moulded poly lactic acid/kenaf fibre (PLA/KF) biocomposite and found that the biocomposite remained amorphous with the fibre content.

Thitithanasarn [15] sandwiched engineering thermoplastics (rPET, PC and Nylon 6) with epoxy and unsaturated polyestertreated jute after cured with room temperature curatives to improve the thermal degradation and interphacial bonding which later failed due to the room temperature curatives used.

In this study, the effects of thermosetting resin cured in-situ and fibre loading of kenaf fibre in engineering thermoplastic poly(acrylonitrile-butadiene-styrene) (ABS) composites were examined physically and mechanically.

\section{Experimental}

\subsection{Materials}

ABS pellets were purchased from Chi Mei Company Malaysia, $3 \mathrm{~mm}$ kenaf fibres (KF) produced from Kenaf 
Fibre Industries Sdn. Bhd. (KFI) Malaysia, sodium hydroxide, 100\% acetic acid, epoxy, curing agent (4,4-diaminodiphenyl sulfone, DDS) and chloroform. All materials were supplied by Science and Engineering Research Centre (SERC) of Engineering Campus, Universiti Sains Malaysia, Nibong Tebal, Malaysia.

\subsection{Surface Treatment and Coating}

Kenaf fibres cut to $3 \mathrm{~mm}$ length were oven dried in the laboratory at $37^{\circ} \mathrm{C}$ for 48 hrs prior to being immersed in $6 \% \mathrm{NaOH}$ for $3 \mathrm{hrs}$. They were then washed and neutralized with $100 \%$ acetic acid and finally washed thoroughly with distilled water until neutral $\mathrm{pH}$ was obtained. The $\mathrm{NaOH}$ treated fibres were oven dried at $80^{\circ} \mathrm{C}$ for 16 hrs. The treated fibres were later coated with 30, 40 and $50 \mathrm{wt} \%$ epoxy resin of very low viscosity thinned with chloroform. The epoxy coated fibres (EKF) were first oven dried between $30^{\circ} \mathrm{C}-40^{\circ} \mathrm{C}$ for 16 hrs and then at $80^{\circ} \mathrm{C}$ for $8 \mathrm{hrs}$ to dry finally.

\subsection{Thermoplastic Preparation}

The engineering thermoplastic $\mathrm{ABS}$ was dried in a vacuum oven at $90^{\circ} \mathrm{C}$ for $3 \mathrm{hrs}$.

\subsection{Compounding and Compression Moulding}

The constituent materials ( $A B S / K F)$ after being dried were melt-mixed using fibre loading of $12 \%$, 30\% and 50\% in an internal mixer (Haake PolyDrive R600) cured with4\% 4,4-diaminodiphenyl sulfone (DDS). The mixing process was performed for 10 mins at a temperature of $230{ }^{\circ} \mathrm{C}$ using a rotator speed of $40 \mathrm{rpm}$. The melt-mixed composites were dried at $60^{\circ} \mathrm{C}$ for $3 \mathrm{~h}$ before they were moulded into sheets with a compression moulding machine (GT 7014-A30C, GOTECH). The composites were pre-heated for 5 mins and compressed at $65 \mathrm{~kg} / \mathrm{cm}^{2}$ pressure for 5 mins at $210^{\circ} \mathrm{C}$. The samples were then cooled under pressure at ambient temperature for 3 mins.

\subsection{Tensile Test}

The specimens of $140 \times 25 \times 1 \mathrm{~mm}$ were prepared for tensile test by cutting with a band saw and tensile test was conducted using the Universal Testing Machine, Instron 3366 at $23^{\circ} \mathrm{C} \pm 2{ }^{\circ} \mathrm{C}$ and $50 \% \pm 5 \%$ relative humidity in accordance to ASTM D882-97 with a gauge length of $100 \mathrm{~mm}$ and cross-head speed of $1 \mathrm{~mm} / \mathrm{min}$. Five measurements were carried out on each sample.

\subsection{Flexural Test}

Three-point bending flexural testing was performed on composites using the same Instron 3366 at $23^{\circ} \mathrm{C} \pm 2{ }^{\circ} \mathrm{C}$ and $50 \% \pm 5 \%$ relative humidity in accordance to ASTM D790, with a support span length of $50 \mathrm{~mm}$ and crossspeed of $5 \mathrm{~mm} / \mathrm{min}$. Five measurements were carried out on each sample.

\subsection{Impact Test}

Izod impact test of un-notched composites samples were performed by using Pendulum Impact Machine (Zwick Roell Group, Germany) according to ASTM D256 with pendulum energy of $7.5 \mathrm{~J}$. The impact strength $\left(\mathrm{kJ} / \mathrm{m}^{2}\right)$ was calculated by dividing the recorded absorbed impact energy by the cross-sectional area of the samples. Five measurements were carried out on each sample.

\subsection{Hardness Test}

The hardness of the composites was determined according to ASTM D2240 D. The hardness of compression moulded flat shaped samples with dimensions (width-22 $\mathrm{mm}$ and thickness-1 $\mathrm{mm}$ ) was determined with the use of the TECLOCK GS-702G TYPE D (Japan) Automatic Digital Hardness Tester. Five measurements were carried out on each sample.

\section{Results and Discussion}

\subsection{The Effect of Epoxy Concentration on Tensile Properties}

The mechanical properties of polymer composites have been found to depend solely on both extent of fibre- 
matrix bonding and load transfer frommatrix to reinforcement. The performance of naturalfibre reinforced polymer composites is controlled by the properties of the fibre-matrix adhesion/bonding (Thakur and Singha, [4]). Figures 1-3 show the effect of thermosetting resin, epoxy on tensile properties of ABS/EKF composites. From Figure 1, it can be observed that tensile strength of composites increase with increasing thermoset loading to a maximum at $40 \%$ concentration, this may be as a result of quality adhesion/bonding between epoxy-fibre but with a $10 \%$ increase, the strength decreased indicating an excessive coating which has in turn reduced the intermolecular bonding between fibre and matrix.

The tensile strain was found to follow almost the same trend if not for $0 \%$ that was with the highest strain indicating a higher strain required when fibres are not resin coated (Figure 2).

Figure 3 shows similar trends with that of tensile strength where epoxy concentrations have increased the modulus from $0 \%$ to $40 \%$ optimum level and thereafter decreased when increased to $50 \%$ epoxy concentration.

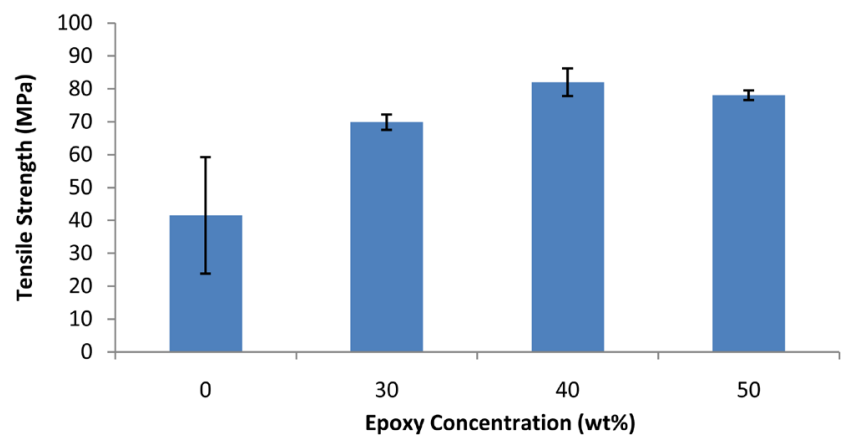

Figure 1. Effect of epoxy concentration on Tensile strength of ABS/ EKF composites.

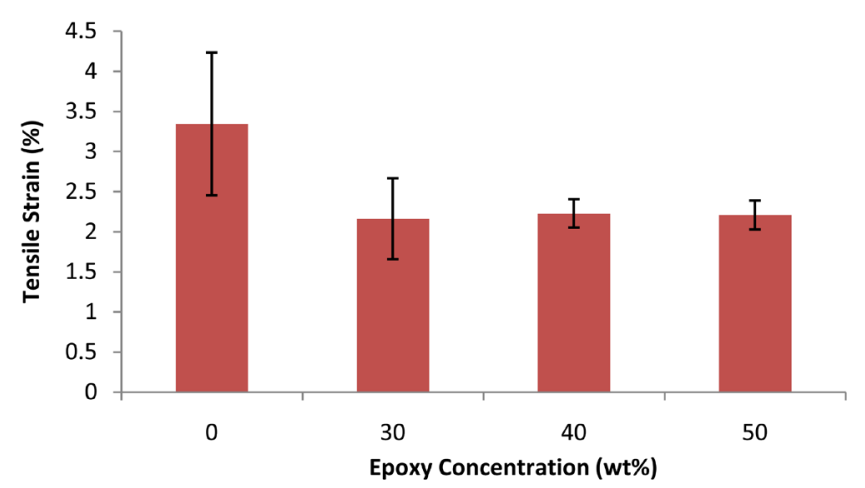

Figure 2. Effect of epoxy concentration on the tensile strain of ABS/ EKF composites.

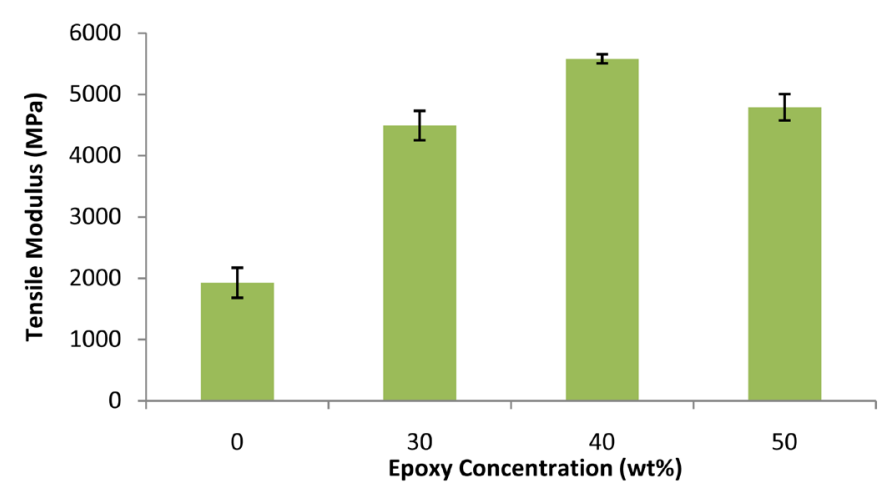

Figure 3. Effect of epoxy concentration on tensile modulus of ABS/ EKF composites. 


\subsection{The Effect of Fibre Loading on Tensile Properties}

The tensile strength showed optimal value at $30 \%$ with addition of fibres from $0 \%$ (Figure 4), indicating that with further addition of fibres up to 50\%, the strength reduced from $73 \mathrm{MPa}$ to $62 \mathrm{MPa}$. This might be due to the strong interfacial bonding built before the increase to $50 \%$ has reduced. Figure 5 relates the tensile strain where the strain decreased with increasing fibre loading while the tensile modulus increased progressively with increasing fibres (Figure 6). This result is as expected and can be attributed to increasing in fibres which is the property that mostly have impact on modulus. Ramakrishna and Rai [16], in their findings from mechanical properties of kenaf fibre-polypropylene composites showed that on increasing the filler content, the tensile strength and modulus of all their composites were found to increase. Also in line with the observation of Huang and Chiou [17] in their study-The Effect of Reprocessing on the EMI shielding effectiveness of Conductive fibre reinforced ABS Composites.

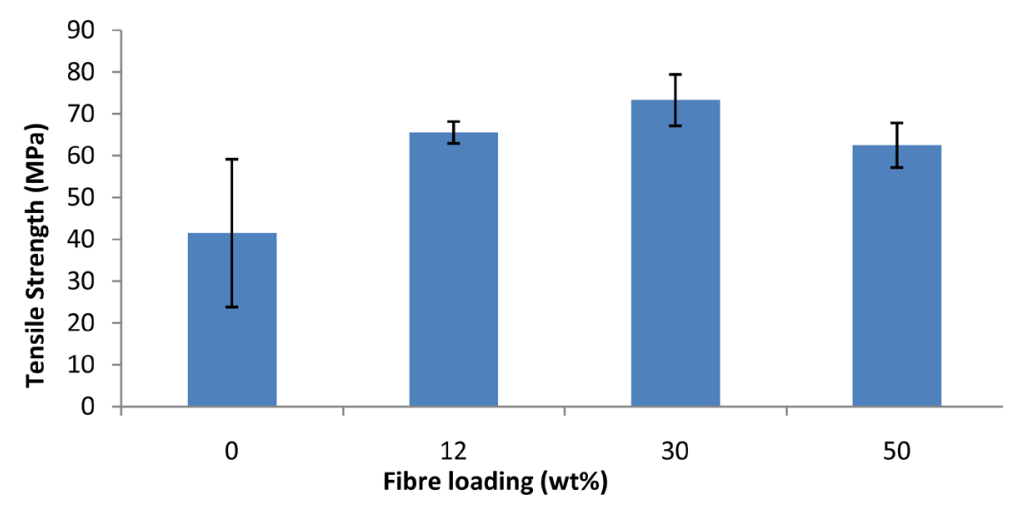

Figure 4. Effect of fibre loading on tensile strength of ABS/EKF composites.

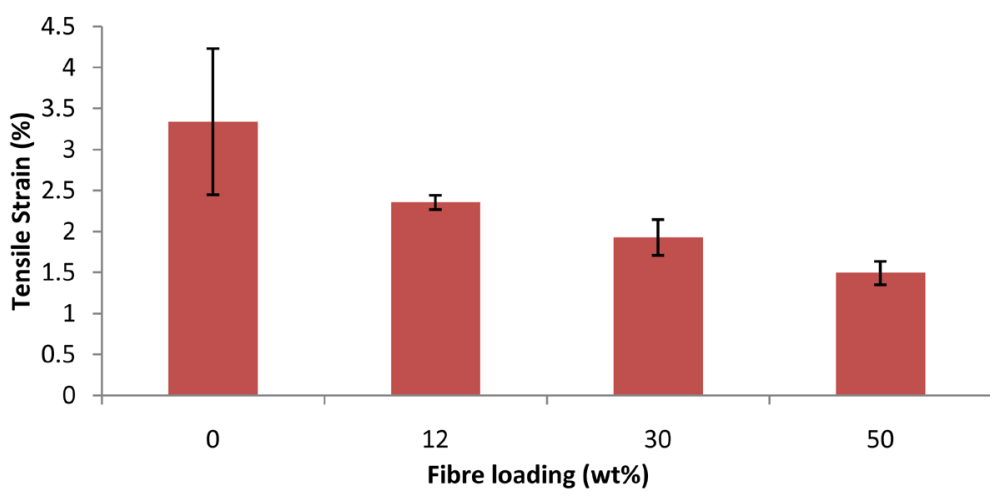

Figure 5. Effect of fibre loading on tensile strain of ABS/EKF composites.

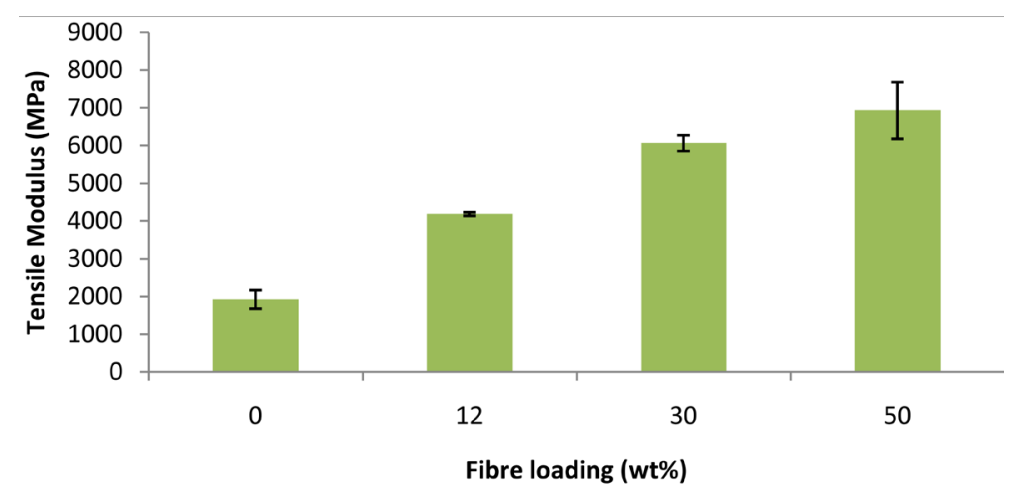

Figure 6. Effect of fibre loading on tensile modulus of ABS/EKF composites. 


\subsection{The Effect of Fibre Loading on Flexural Properties}

The effect of fibre loading on flexural properties (Figure 7 and Figure 8) showed significant reduction and improvement of flexural strength and modulus respectively from 12 to $50 \mathrm{wt} \%$ fibre loading. The flexural strength of the composites from Figure 7, decreased with increasing fibre loading which might be due to insufficient wetting of the incorporated fibres by the thermoplastic matrix in the presence of fibre bundles and more fibrefibre interactions as the loading increases. Rowell et al., [10] explained that it is usually the lignin that is responsible for the combination of individual fibre together to make fibre bundles. Moh'd Ishak et al., [18] further explained that fibre-fibre adhesion in fibre bundles reduces the contact area between fibres and the matrix which can cause poor stress transfer from the matrix phase to the dispersed fibres. The modulus increased with increasing fibre loading as expected, the result is depicted in Figure 8. This may be as a result of the same reason that fibres increased the modulus of composites. Similar observations were made by Dhal and Mishra [19] and Ku et al., [20] but in contrast to Elbadry et al., [21].

\subsection{Impact and Hardness Properties of the Composites}

When a composite is subjected to an impact, rapid crack propagation is initiated through the material. When this type of crack propagation encounters filler particles in the filled composites, the filler particles can absorb the energy and stop the propagation, if filler matrix interaction is strong (Ramakrishna and Rai, [16]). Figure 9 and Figure 10 indicate the impact and hardness values of the composites. From Figure 9, the values of impact do not exhibit a phenomenal trend during the fibre loading as it has the highest value, $24.14 \mathrm{~kJ} / \mathrm{m}^{2}$ at $12 \mathrm{wt} \%$ fibre loading, decreased to 15.12 for $30 \mathrm{wt} \%$ and later increased marginally to $16.71 \mathrm{~kJ} / \mathrm{m}^{2}$ when at $50 \mathrm{wt} \%$ loading. This might be attributed to the fact that at $12 \%$ fibre loading, more energy might be absorbed during the impact failure than other loadings and the matrix related energy absorbing mechanism might probably dominates than that of the energy absorbing mechanism of the composite. Also agglomeration of fibres at higher loading can be

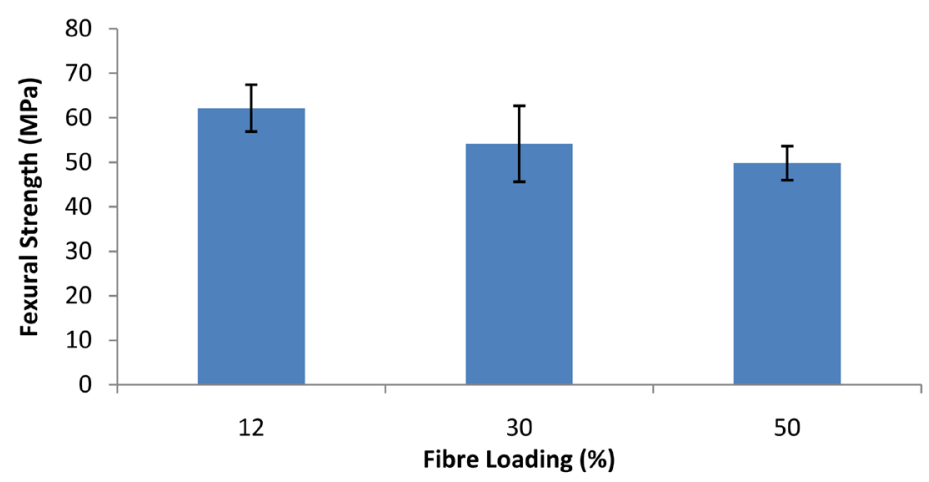

Figure 7. Effect of fibre loading on flexural strength of ABS/EKF of cured composites.

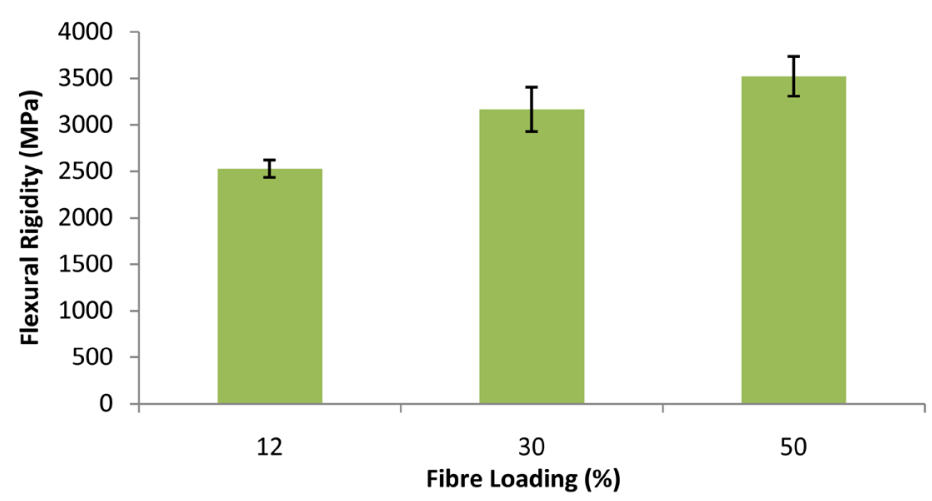

Figure 8. Effect of fibre loading on flexural modulus of ABS/EKF of cured composites. 


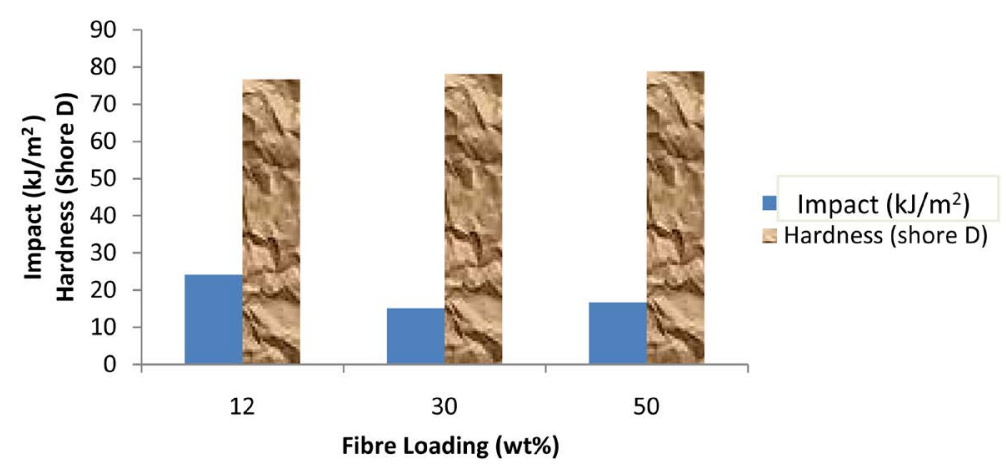

Figure 9. Effect of fibre loading on impact strength and hardness of ABS/ EKF cured composites.

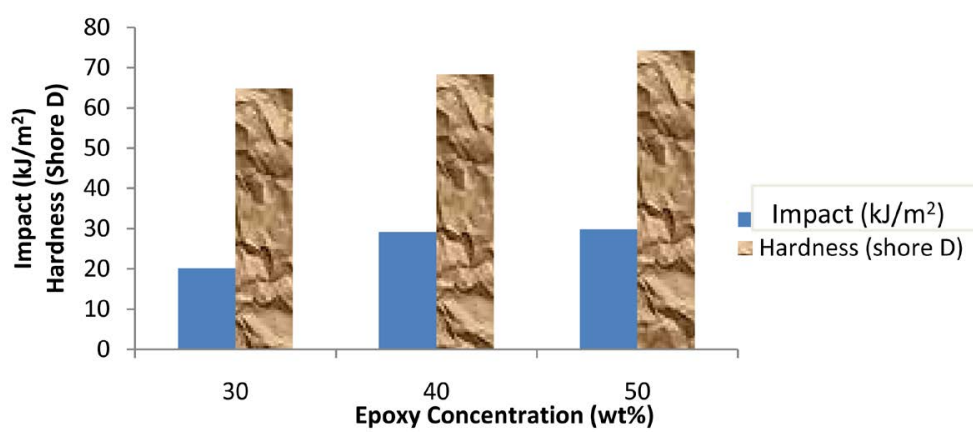

Figure 10. Effect of epoxy concentration on impact strength and hardness of ABS/EKF composites.

resulted (Tay et al., [22]). As regarding hardness, there were proportional increases with increasing fibre loading. This may be due to stronger interface bonding between the fibres and cured epoxy resin.

However, with the epoxy concentration in Figure 10, the impact strength increased with increasing thermoset (epoxy). These can be due to the encapsulation of fibres by epoxy which bind the fibres together to prevent their free movement. In the case of hardness, there was proportional increase with increasing thermoset concentration which can be attributed to the intermolecular bonding between epoxy and fibre.

\section{Conclusion}

The mechanical properties of cured epoxy coated KF-engineering thermoplastic ABS composites while increasing the epoxy and fibres content were studied in this research with these findings. Coating of bast KF with epoxy resin had made the natural fibre to withstand higher temperature without degradation of the fibres during compounding at the internal mixer if epoxy treated. Tensile strength has increased with increase in both epoxy and fibre loadings to a maximum point. Impact increased with epoxy loading as hardness increased with both parameter loadings. The optimum tensile strength was observed at $40 \mathrm{wt} \%$ epoxy and $30 \mathrm{wt} \%$ fibre loading. It has been established that epoxy coated KF can be incorporated into a higher processing temperature engineering thermoplastic, ABS without degradation of the fibres.

\section{Acknowledgements}

The authors acknowledged the support of this work from Science and Engineering Research Centre (SERC) of Universiti Sains Malaysia, Engineering Campus for providing all the research materials and equipment. Also appreciate Ahmadu Bello University, Zaria Nigeria for supporting the study.

\section{References}

[1] Hedrick, J.L., Yilgor, I., Wilkes, G.L. and McGrath, J.E. (1985) Chemical Modification of Matrix Resin Networks with Engineering Thermoplastics 1. Phenolic Hydroxyl Terminated Poly(Aryl Ether Sulfone)-Epoxy Systems. Polymer 
Bulletin, 13, 201-208. http://dx.doi.org/10.1007/BF00254652

[2] George, J., Ivens, J. and Verpoest, I. (1999) Mechanical Properties of Flax Fibre Reinforced Epoxycomposites. Die Angewandlte Makromolekulare Chemie, 272, 41-45. http://dx.doi.org/10.1002/(SICI)1522-9505(19991201)272:1<41::AID-APMC41>3.0.CO;2-X

[3] Bos, H.L. and Donald, A.M. (1999) In Situ ESEM Study of the Deformation of Elementary Flax Fibres. Journal of Material Science, 34, 3029-3034. http://dx.doi.org/10.1023/A:1004650126890

[4] Thakur, V.K. and Shingha, A.S. (2010) Physico-Chemical and Mechanical Characterization of Natural Fibre Reinforced Polymer Composites. Iranian Polymer Journal, 19, 3-16.

[5] Kozlowski, R. and Wladyka-Przybylak, M. (2004) Uses of Natural Fibre Reinforced Plastics. In: Wallenberger, F.T. and Weston, N.E., Eds., Natural Fibres, Plastics and Composites, Kluwer Academic Publishers, Dordrecht. http://dx.doi.org/10.1007/978-1-4419-9050-1_14

[6] Kozlowski, R. and Wladyka-Przybylak, M. (2006) Composites Reinforced with Lignocellulosic Fibres. Proceedings of the 8th Pacific Rim Bio-Based Composites Symposium, Kuala Lumpur.

[7] Bledzki, A.K. and Gassan, J. (1997) Natural Fibre Reinforced Plastics. In: Cheremisinoff, N.P., Ed., Handbook of Engineering Polymeric Materials, Marcel Dekker, Inc., New York.

[8] Thomas, S. (2002) Cellulose Fibre Reinforced Composites: New Challenges and Opportunities. 4th International Wood and Natural Fibre Composites Symposium, Kassel.

[9] Aji, I.S., Sapuan, S.M., Zainuddin, E.S. and Abdan, K. (2009) Kenaf Fibres as Reinforcement for Polymeric Composites: A Review. International Journal of Mechanical and Materials Engineering, 4, 239-248.

[10] Rowell, R.M., Sanadi, A.R., Jacobson, R.E. and Caulfield, D.F. (1999) In: Kenaf Properties, Processing and Products. Mississippi State University, Ag and Bio Engineering, Chap 32, 381-392.

[11] Sanadi, A.R., Caulfield, D.F., Jacobson, R.E. and Rowell, R.M. (1995) Renewable Agricultural Fibres as Reinforcing Fillers in Plastics: Mechanical Properties of Kenaf Fibre-Polypropylene Composites. Industrial \& Engineering Chemistry Research, 34, 1889-1896. http://dx.doi.org/10.1021/ie00044a041

[12] El-Shekeil, Y.A., Sapuan, S.M., Abdan, K. and Zainudin, E.S. (2011) Development of a New Kenaf Bast Fibre-Reinforced Thermoplastic Polyurethane Composite. BioResources, 6, 4662-4672.

[13] Karina, M., Onggo, H. and Syampurwadi, A. (2007) Physical and Mechanical Properties of Natural Fibres Filled Polypropylene Composites and Its Recycle. Journal of Biological Sciences, 7, 393-396.

[14] Anuar, H. and Zaraida, A. (2011) Thermal Properties of Injection Moulded Polylactic Acid-Kenaf Fibre Biocomposites. Malaysian Polymer Journal, 6, 51-57.

[15] Smith, T. (2011) Development of Natural Fibre Reinforced Composites with Engineering Thermoplastic Marices. A PhD Project in the Department of Advance Fibro-Science, Kyoto Institute of Technology, Kyoto.

[16] Ramakrishna, H.V. and Rai, S.K. (2006) Effect on Mechanical Properties and Water Absorption of Granite Powder Composites on Toughening Epoxy with Unsaturated Polyester and Unsaturated Polyester with Epoxy Resin. Journal of Reinforced Plastics and Composites, 26, 17-32.

[17] Huang, C.-Y. and Chiou, T.-W. (1998) The Effect of Reprocessing on the EMI Shielding Effectiveness of Conductive Fibre Reinforced ABS Composites. European Polymer Journal, 34, 37-43. http://dx.doi.org/10.1016/S0014-3057(97)00068-2

[18] Moh'd Ishak, Z.A., Aminullah, A., Ismail, H. and Rozman, H.D. (1997) Effect of Silane-Based Compactibilizers on Mechanical Properties of Oil Palm Empty Fruit Bunch Filled HDPE Composites. Journal of Applied Polymer Science, 68, 2189-2203.

[19] Dhal, J.P. and Mishra, S.C. (2013) Processing and Properties of Natural Fiber-Reinforced Polymer Composite. Journal of Materials, 2013, Article ID: 297213.

[20] Ku, H., Wang, H., Pattarachaiyakoop, N. and Trada, M. (2010) A Review on the Tensile Properties of Natural Fibre Reinforced Polymer Composites. www.eprits.usq.edu.au.18884/

[21] Elbadry, E.A., Aly-Hassan, M.S. and Hamada, H. (2012) Mechanical Properties of Natural Jute Fabric/Jute Mat Fibre Reinforced Polymer Matrix Hybrid Composites. Advances in Mechanical Engineering, 4, Article ID: 354547. http://dx.doi.org/10.1155/2012/354547

[22] Tay, G.S., Azniwati, A.A., Azizah, A.B., Rozman, H.D. and Musa, L. (2012) The Flexural and Impact Properties of Kenaf-Polypropylene Composites Filled with Montmorillonite Filler. Polymer-Plastics Technology and Engineering, 51, 208-213. http://dx.doi.org/10.1080/03602559.2011.625376 